\title{
PENERAPAN POMPA AIR TENAGA MATAHARI UNTUK AIR WUDHU MUSHOLLA PANTAI UNGAPAN KABUPATEN MALANG
}

\author{
Fathoni $^{1}$, Agus Pacoyo ${ }^{2}$, Budhy Setiawan ${ }^{3}$, Hariadi Singgih ${ }^{4}$, Sungkono $^{5}$, Abim Ridho Gautama ${ }^{4}$ \\ $1,2,3,4,5$ ) Jurusan Teknik Elektro, Politeknik Negeri Malang \\ $\left.{ }^{4}\right)$ Mahasiswa D4 Teknik Elektronika Politeknik Negeri Malang \\ pakfapyrus@yahoo.com
}

\begin{abstract}
Abstrak - Permasalahan yang ada di musholla umum pantai Ungapan Kabupaten Malang adalah ketidak tetapan tersedianya air wudhu, terutama pada harihari kerja atau bukan hari libur ataupun hari raya. Hal ni disebabkan oleh ketidak beradaan pemilik warung yang lokasinya berada di sebelah utara musholla yang juga menjadi penanggung jawabnya. Dengan memanfaatkan sinar matahari sebagai sumber daya dapat digunakan untuk menghidupkan pompa air dc. Agar ketersediaan air wudhu terjaga, perlu ditambahkan rangkaian kendali otomatis yang akan menhidupkan pompa air saat isi tandon berkurang hingga level terendah sedangkan tegangan baterai cukup. Rangkaian kendali dibangun dari pembanding tegangan dan susunan saklar seri, saklar tandon dan rele. Saklar yang dipasang pada tandon dilengkapi dengan 2 buah pelampung yang terhubung dengan tali pada mekanis saklar sehingga mempunyai karakteristik on/off yang berdasar pada level air. Saklar tandon akan on jka permukaan air kurang dari level minimalnya dan baru akan off jika melewati level maksimalnya. Penetapan posisi level atas dan bawah dapat dilakuan dengan mengatur panjang pelampung. Jika saklar tandon on sedangkan tegangan baterai bernilai di bawah 11 volt maka, pompa air tidak dapat menyala. Pompa air dc jenis celup mampunyai debit air keluaran yang tergantung ketinggian dorongnya. Pada ketinggian pipa hingga 4 meter, debit air keluaran hanya sekitar 25 lt per menit. Dengan perkiraan pemakaian air wudhu 500 lt per hari maka pompa air akan bekerja selama 20 menit dan jika arus dc pompa sebesar 5A maka konsumsi arus adalah 1,5 Amper jam. Panel surya 50 WP dapat menghasilkan arus pengisian hingga 1,8A dan pada hari terang dapat mengisi baterai rata-rata selama 4 jam. Dari pengisian baterai tersebut maka pompa air dapat mengisi tandon dengan benar kecuali jika hari mendung. Untuk mengatasi masalah kekurangan pasokan air di hari-hari ramai pengunjung, pipa saluran keluaran dari tandon ke kran wudhu disambungan ke saluran keluaran tandon lama dengan tambahan katup satu arah atau tosen klep. Air hanya dapat mengalir ke saluran wudhu dan tidak dapat masuk ke tandon lama. Pada hari-hari ramai pengunjung, kekurangan air wudhu dapat dipenuhi oleh aliran dari tandon lama karena penanggung jawab musholla sedang berada di lokasi.
\end{abstract}

Kata kunci: Panel surya, otomatis, pompa air, wudhu

\section{PENDAHULUAN}

\subsection{Latar Belakang}

Lokasi obyek PkM adalah musholla umum di pantai Ungapan Kabupaten Malang. Tempat wudhu terletak di sebelah timur musholla berjajar dengan kamar mandi dan berada pada dasar bukit kecil di sebelah timur pantai Ungapan. Oleh masyarakat sekitar, bukit kapur tersebut dinamai sebagai Gunung Getun. Nama tersebut diberikan karena para pendaki banyak yang kecewa setelah sampai di puncak bukit dan tidak mendapati sesuatu yang istimewa. Getun dalam bahasa jawa berarti kecewa. Kontur tanah lokasi berdirinya bangunan musholla mempuna kemiringan hingga $60^{\circ}$ dengan lantai batu kapur yang tidak rata. Lokasi permukaan tanah kapur ini memungkinkan penempatan tandon air pada sisi bukit yang ketinggiannya di atas kran untuk wudhu. Kontruksi penyangga tandon disesuaikan dengan keadaan permukaan tanah atau kontur permukaan dan dilakukan pengeprasan, perataan dan pengecoran ringan. Denah musholla, sumur dan tempat wudhu jika dilihat dari samping ditunjukkan dalam Gambar 1.

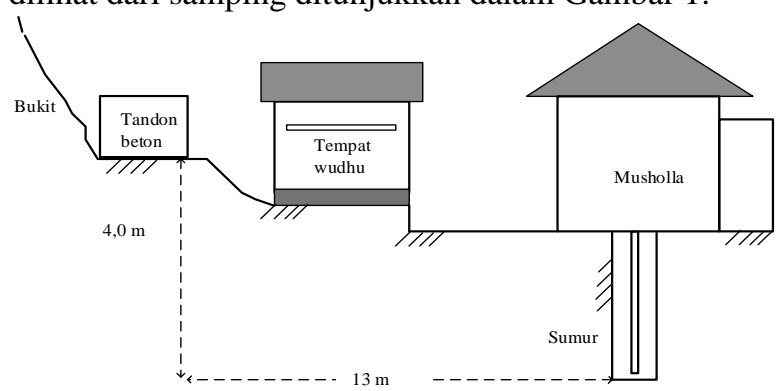

Gambar 1 Kontur lokasi PkM

Dengan memberikan pengetahuan tentang panel surya dan cara kerjanya serta prosedur pemasangan diharapkan anggota kelompok pedagang makanan di lingkungan pantai dapat menerapkan sumber daya matahari untuk keperluan listrik daya rendah. Selain ramah lingkungan, energi yang dihasilkan juga gratis kecuali investasi awal seperti pengadaan panel surya, baterai dan instalasi lampu. Pemahaman pemanfaatan sumber daya alam yang ramah lingkungan sangat penting mengingat semakin mahalnya energi listrik saat ini. Energi dari cahaya matahari adalah ramah lingungan dan gratis, seperti halnya angin pantai walau arah dan kecepatannya tidak konstan. 


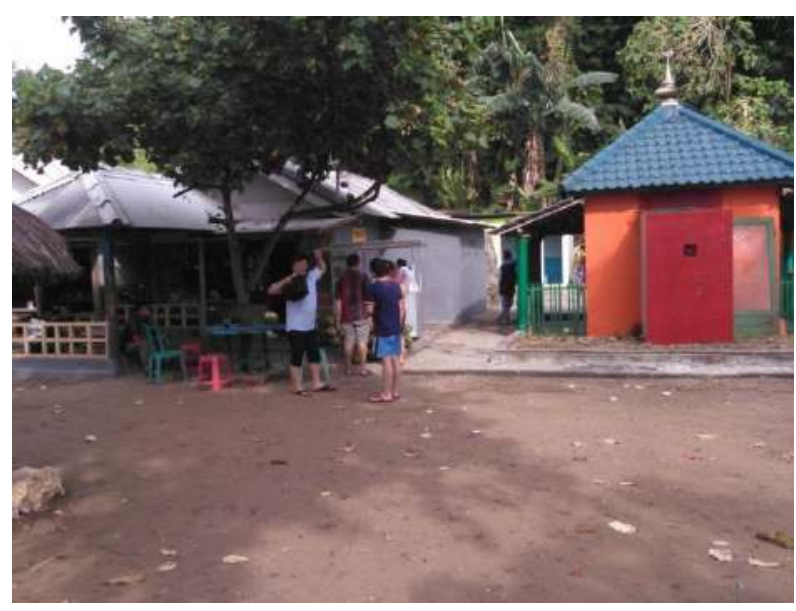

Gambar 2 Musholla di pantai Ungapan

Musholla umum di pantai Ungapan sebelum dipasangi panel surya ditunjukkan dalam Gambar 2. Cahaya matahari di atas musholla terlihat sangat berlimpah. Gambar tersebut diambil pada pagi hari sekitar jam 11.00 wib di awal bulan Juli 2017. Terlihat tidak ada penghalang cahaya matahari yang menimpa genting sebelah utara dan barat. Jika panel surya diletakkan di bagian tersebut maka pencahayaan akan optimal dan arus pengisian baterai bisa juga optimal.

\subsection{Permasalahan Mitra}

Permasalahan teknis yang ada di musholla pantai Ungapan Kabupaten Malang adalah masalah penerangan dan air wudhu. Hal ini dikarenakan aliran listrik khusus musholla tidak tersedia, sedang jaringan listrik di warung makanan di sekitar mushola juga belum terbangun dengan resmi. Aliran listrik juga terkadang ada dan terkadang tidak.

Permasalahan lain adalah, keberadaan pemilik warung sebelah kiri dan kanan musholla juga tidak tetap karena bangunan warung tidak dijadikan tempat tinggal dan hanya dihuni pada saat hari libur atau hari berkeramaian lainnya seperti hari libur, ada kegiatan perkemahan, komunitas sosial dan sebagainya. Hal ini menjadikan penerangan musholla malam hari serta ketersediaan air wudhu menjadi tidak selalu tersedia. Walaupun tidak besar, biaya listrik juga membebani keuangan warga sekitar mushola. Dengan kegiatan PKM diharapkan dapat mengurangi masalah kelistrikan di fasilitas umum khususnya musholla di pantai Ungapan.

\section{KAJIAN PUSTAKA}

Pemanfaatan panel surya dan baterai sebagai sumber listrik dc banyak digunakan untuk terapan lampu penerangan dan pompa air, terutama yang memerlukan sumber daya dc.

\subsection{Pompa Air dc}

Ada banyak macam pompa air listrik dc yang tersedia di pasaran umum ataupun on-line. Jenis celup (submersible pump) ataupun permukaan serta dengan variasi daya dan kemampuan pengalirannya. Umumnya pompa air dc mempunyai spesifkasi tegangan 12 volt dan 24 volt. Pompa air dc kecil 12 volt dengan daya 60 watt jenis celup merk Mollar dengan kode MLR-WP027 ditunjukkan dalam Gambar 3. Diameter pipa saluran keluaran bawaan pabrik dari pompa air celup tersebut adalah 1 inchi. Debit air yang dihasilkan dari pompa air dc jenis celup dipengaruhi oleh ketinggian dorongnya. Semakin tinggi ujung saluran keluaran, debit air yang dihasilkan menjadi semakin rendah. Untuk menaikkan daya dorong dapat dilakukan dengan mengurangi debit keluaran. Cara termudah adalah mengganti saluran keluaran dengan saluran berukuran diameter yang lebih kecil.

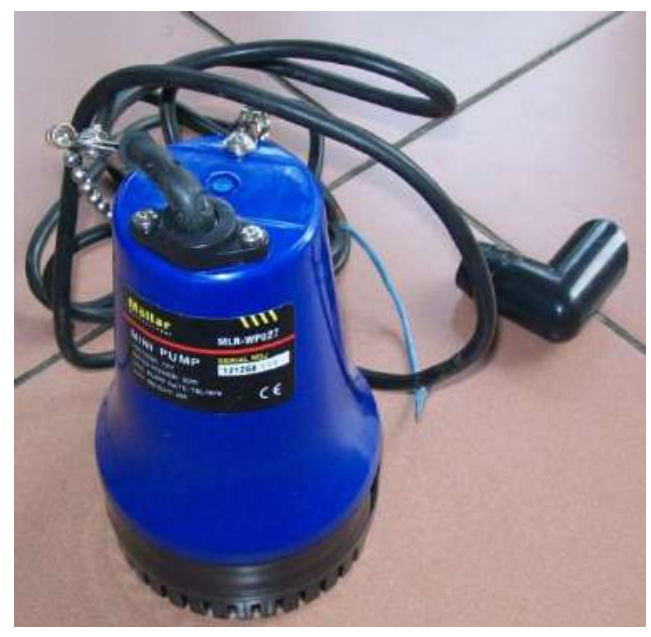

Gambar 3 Pompa dc 60 watt

\subsection{Panel Surya}

Bedasar penelitan Teguh Utomo (2009) radiasi matahari dan energi yang dihasilkan sepanjang tahun di daerah Malang ditunjukkan dalam Tabel 1. Berdasar data Tabel 1 menunjukkan bahwa radiasi matahari dapat menghasilkan daya listrik sepanjang tahun. Puncak daya yang dihasilkan adalah bulan Juli sedang hasil daya terendah pada bulan Desember.

Tabel 1 Radiasi matahari dan daya output panel surya

\begin{tabular}{|l|l|l|}
\hline Bulan & $\begin{array}{l}\text { Radiasi Matahari } \\
\mathrm{kWH} / \mathrm{m}^{2} / \text { hari }\end{array}$ & $\begin{array}{l}\text { Energi yang dihasilkan 2 } \\
\text { modul panel surya } \\
(\mathrm{kWH})\end{array}$ \\
\hline Januari & 4.421 & 0.63615 \\
\hline Februari & 4.044 & 0.6066 \\
\hline Maret & 4.063 & 0.60945 \\
\hline April & 5.170 & 0.7755 \\
\hline Mei & 5.974 & 0.8961 \\
\hline Juni & 6.084 & 0.9126 \\
\hline Juli & 6.305 & 0.94575 \\
\hline Agustus & 6.099 & 0.91485 \\
\hline September & 4.464 & 0.6696 \\
\hline Oktober & 4.124 & 0.6186 \\
\hline November & 4.340 & 0.651 \\
\hline Desember & 3.178 & 0.4767 \\
\hline
\end{tabular}

Kajian arus pengisian baterai 12 volt dari panel surya 50WP jenis polycristaline yang dilakukan pada bulan Juli 2017, pukul 8.30 hingga pukul 15.00 dengan sudut hadap tegak lurus arah cahaya matahari. Arus pengisian hingga 1,8A. Puncak arus pengisian baterai terjadi pada waktu penyinaran sekitar pukul 11.00. 
Bentuk fisik panel surya 50WP yang digunakan dalam kegiatan PKM ini dtunjukkan dalam Gambar 4.

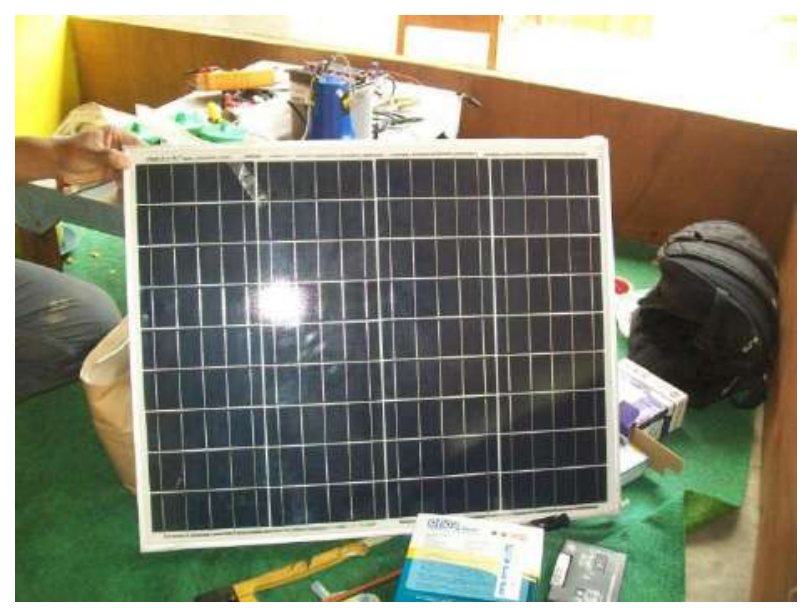

Gambar 4 Panel surya 50WP

\section{SOLUSI}

Solusi dari permasalahan mitra tersebut adalah dengan memasang panel surya, baterai dan pompa. Diagram blok sistem pompa air dc tenaga matahari ditunjukkan dalam Gambar 3. Tandon kecil dibedakan dari tandon lama yang berupa bak beton dan sudah bocor. Dengan tandon khusus air wudhu yang juga tetap terhubung ke tandon agar memungkinkan ketersediaan air wudhu lebih terjaga. Penyambungan pipa saluran dari tandon lama dilengkapi katup satu arah atau tosen klep agar air tandon baru tidak akan mengalir ke tandon lama sedangkan air dari tandon lama bisa mengalir ke tandon baru. Skema rangkaian kendali ditunjukkan dalam Gambar 4.

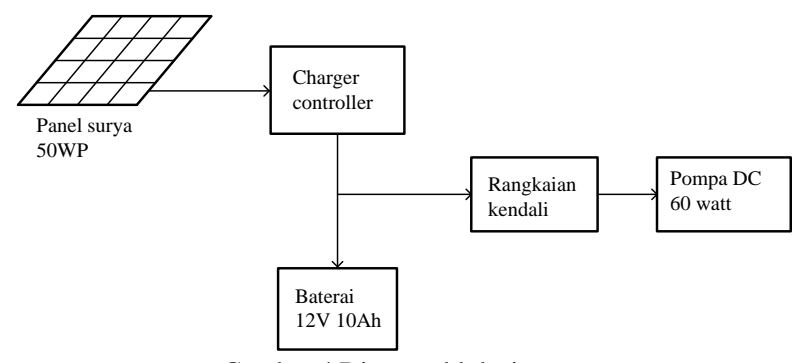

Gambar 4 Diagram blok sistem

Estimasi daya yang dihasilkan oleh panel surya 50WP dengan arus output 1,5 A dan waktu penyinaran rata-rata 4 per hari adalah, $6 \mathrm{~A}$. Konsumsi arus untuk pompa de dihitung berdasar perkiraan jumlah pemakai dan waktu pemakaian. Debit air dihitung berdasar ketinggian muka tandon terhadap pompa dan volume air yang dihasilkan dapat dihitung. Dari pengukuran di lapangan diperloleh data ketinggian tandon dari sumur adalah $4 \mathrm{~m}$ sehingga dalam keadaan ideal debit air adalah 25 lt per menit.

Jika volume air wudhu per orang adalah 5 lt maka untuk 20 orang per waktu sholat adalah $100 \mathrm{lt}$ dan untuk $5 \mathrm{x}$ waktu sholat menjadi 500 lt. Waktu pengisian yang diperlukan untuk mengisi tandon adalah $t_{\mathrm{on}}=(500 / 25)$ menit $=20$ menit. Jika diperlukan arus pompa $5 \mathrm{~A}$ per jam maka kebutuhan arus adalah 0,3 jam $\times 5 \mathrm{~A} \approx 1,5 \mathrm{Ah}$.

\subsection{Pelaksanaan PKM}

Jadwal pelaksanaan kegiatan PKM ditunjukkan dalam Tabel 2. Karena jarak tempuh dari kampus Politeknik Negeri Malang ke lokasi kegiatan PkM cukup jauh atau sekitar $80 \mathrm{~km}$ maka waktu pelaksanaan kegiatan PKM dilakukan sebanyak 4 kali pertemuan.

Tabel 2 Jadwal pelaksanaan PKM

\begin{tabular}{|l|l|l|l|}
\hline Waktu & Kegiatan & Metode & Instruk. \\
\hline $\begin{array}{l}\text { Selasa } \\
\text { 20/8/2019 }\end{array}$ & $\begin{array}{l}\text { Studi lapangan } \\
\text { Perencanaan sistem }\end{array}$ & $\begin{array}{l}\text { Diskusi dan } \\
\text { Tanya- } \\
\text { jawab }\end{array}$ & Team \\
\hline $\begin{array}{l}\text { Minggu } \\
\text { 9/9/2019 }\end{array}$ & $\begin{array}{l}\text { Pemasangan panel surya } \\
\text { dan baterai } \\
\text { Instalasi pipa }\end{array}$ & $\begin{array}{l}\text { Praktek dan } \\
\text { Tanya } \\
\text { jawab }\end{array}$ & Team \\
\hline $\begin{array}{l}\text { Jum'at } \\
\text { 13/9/2019 }\end{array}$ & $\begin{array}{l}\text { Instalasi pipa dan tandon } \\
\text { Pengujian }\end{array}$ & $\begin{array}{l}\text { Praktek dan } \\
\text { Tanya- } \\
\text { jawab }\end{array}$ & Team \\
\hline $\begin{array}{l}\text { Minggu } \\
\text { 2/10/2019 }\end{array}$ & Finshing & Praktek & Team \\
\hline
\end{tabular}

\subsection{Pemasangan Panel Surya}

Panel surya dipasang di atas batu karang yang letaknya tepat di depan kamar mandi dan di sebelah utara tempat wudhu. Baterai dan solar charger controller ditempatkan di dalam rumah penanggung jawab musholla atau di dalam warung. Ketinggian batu karang kira-kira 2,5 meter dari tanah dasar dengan permukaan yang tidak rata, penyangga panel dibuat dari aluminium dengan penguncian mur-baut.

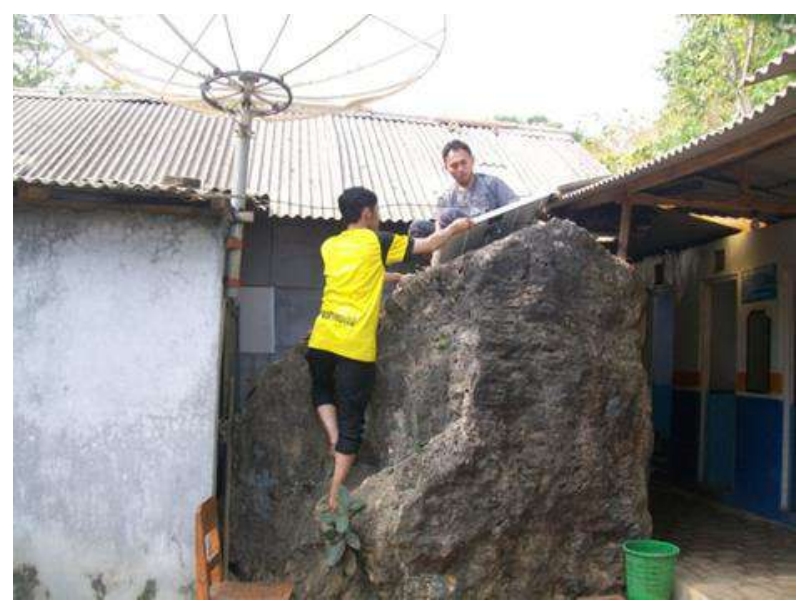

Gambar 5 Pemasangan panel surya

\subsection{Instalasi Pipa Air}

Pemasangan tandon baru yang dikhususkan untuk cadangan aitr wudhu tersebut didasarkan pada keadaan tandon lama yang bocor. Karena ukurannya yang besar, 1 x 1 x 0,8 meter dan terbuat dari tembok batu bata tanpa besi cor sehingga perbaikannya agak susah, Tandon air wudhu mempunyai volume sekitar 90 liter terbuat dari plastik dan dipasang sejajar tandon beton. Saluran keluaran dari tandon air wudhu tetap terhubung ke saluran keluaran tandon lama dengan tambahan katup satu arah. Aliran dari tandon lama tetap bisa ke kran wudhu tapi tandon air wudhu tidak bisa mengalir ke tandon kamar mandi. Diagram blok instalasi air ditunjukkan dalam Gambar 6. 


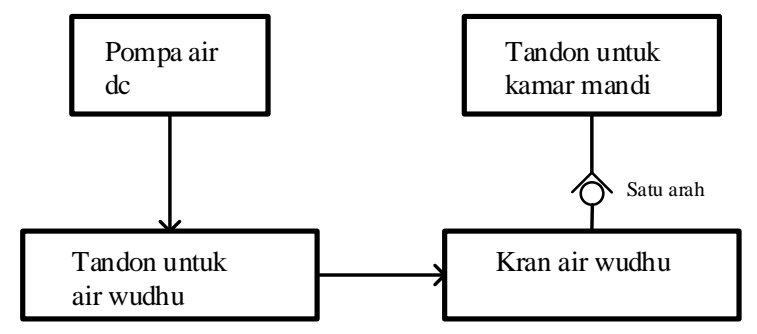

Gambar 6 Diagram aliran air

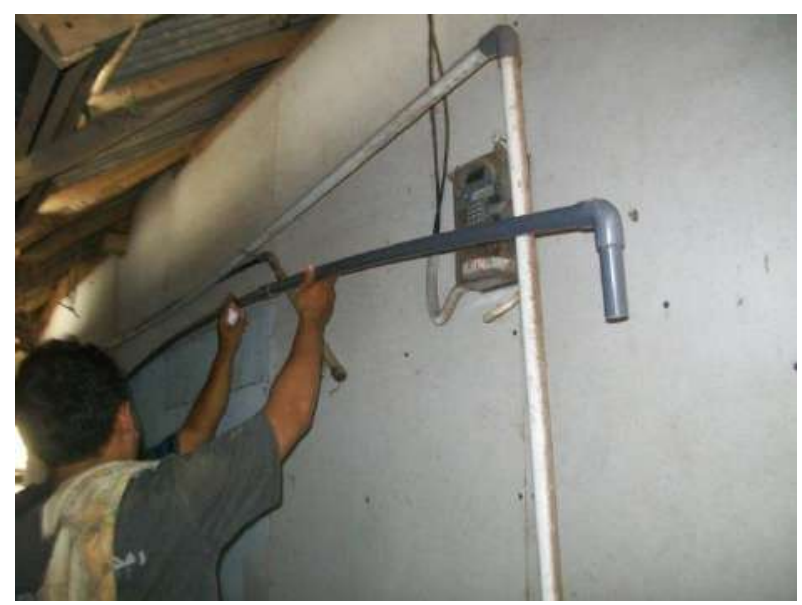

Gambar 7 Pemasangan pipa air

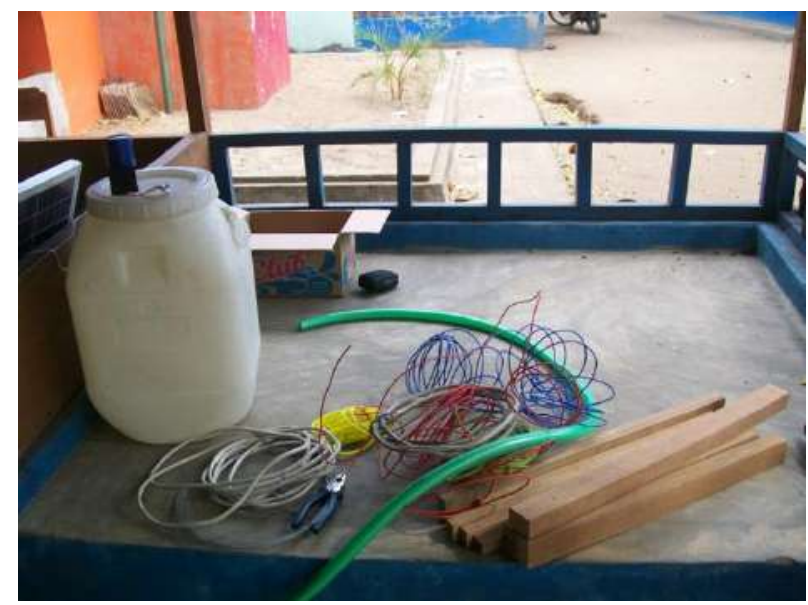

Gambar 8 Persiapan pemasangan tandon

\subsection{Rangkaian Kendali Pompa}

Agar pompa air dapat bekerja secara otomatis maka perlu dipasang saklar yang bekerja on dan off berdasar pada level permuaan air. Saklar dipasang di tandon dan diberi pelampung ganda. Prinsip kerja saklar sebagaimana rangkaian pembanding dengan hysteresis. Dua buah pelampung dihubungkan dengan tali nylon yang flexible. Saklar hanya akan on jika kedua pelampung dalam keadaan tidak mengambang atau cukup berbobot untuk menarik sumbu yang terhubung pada mekanis saklar dan saklar akan off jika kedua pelampung mengapung. Kedua pelampung menjadi titik atau level air pada pengaturan tersebut.

Pompa air akan on dan off pada titk yang tidak sama. Pada saat permukaan air lebih rendah dari level bawah, pompa air akan on dan akan off saat permukaan air melewati level atas. Pengaturan jarak pelampung dapat dilakukan dengan memperpanjang jarak diantara pelampung atas dan bawah serta jarak terhadap pusat di atas. Pengaturan level air untuk pompa air on maupun off dapat dilakukan sendiri oleh pengguna. Pada jens saklar berpelampung yang lain, pelampung dibuat berlobang dengan penutup baut plastic agar dapat diisi air oleh pengguna untuk mengatur bobot pelampung.

Terminal untuk pengawatan dibuat tertutup agar tidak terkena air hujan karena umumnya tandon air dipasang di luar rumah atau pada tempat yang terbuka. Skema rangkaian saklar dengan pelampung dan grafik hysteresis ditunjukkan dalam Gambar 2.4 sedangkan bentuk fisiknya ditunjukkan dalam Gambar 2.5. Penutup saklar dan terminal kabel berupa tabung berwarna biru sedangkan dua buah pelampung berwarna putih.

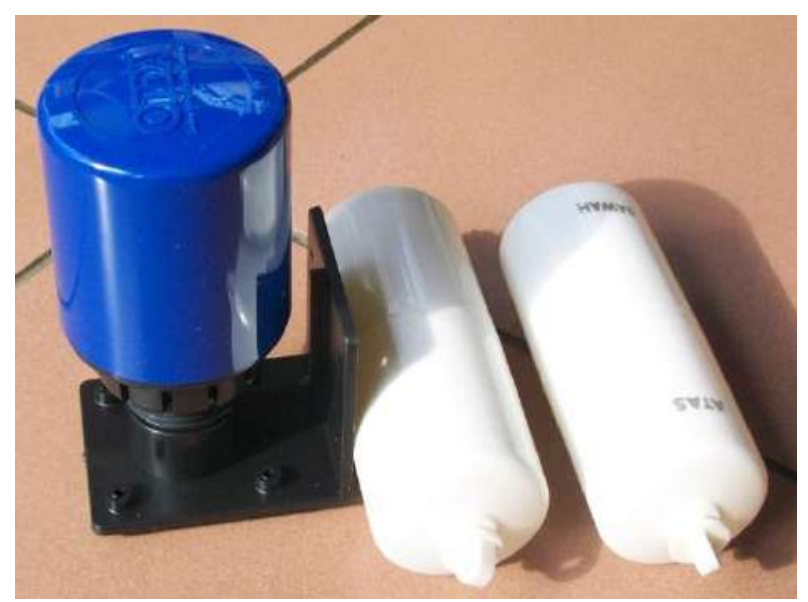

Gambar 9 Saklar tandon

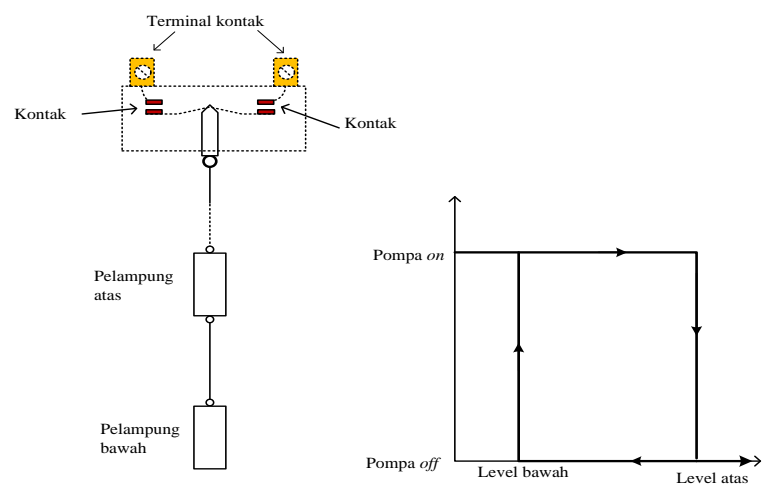

Gambar 10 Skema dan karakteristik saklar tandon

Penyambungan kabel ke terminal dilakukan setelah panel terpasang sempurna. Pengecekan ulang sambungan dilakuan pada ujung kabel yang terhubung ke rangkaian pengatur pengisian baterai. Untuk mengurangi tegangan jatuh pada jalur instalasi yang menjadi rugi daya maka dipilih kabel pejal dengan diameter 1,5 mm. Panjang jalur kabel instalasi diusahakan untuk jarak terpendek. Terminal sambungan kabel instalasi ditempatkan di dinding tembok dan bukan di kayu atap serta dibungkus isolasi kabel yang kuat agar terhindar dari kebakaran jika terjadi hubungan arus pendek. 


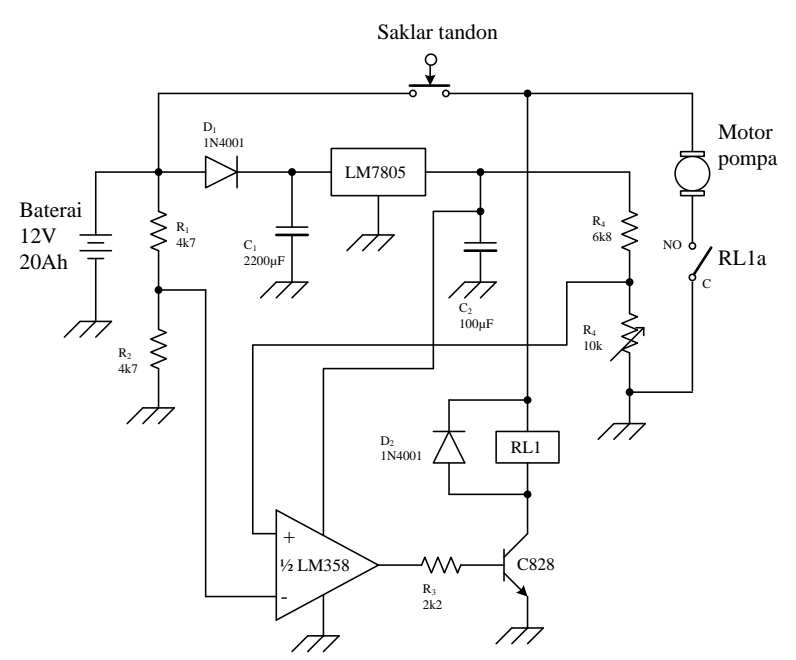

Gambar 11 Skema rangkaian kendali pompa

\section{SIMPULAN DAN SARAN}

Berdasar pengamatan pelaksana pada kegiatan PKM yang dilakukan di pantai Ungapan Kabupaten Malang dapat diambil simpulan dan saran.

\subsection{Simpulan}

Pemasangan pompa air dc untuk penyedia air wudhu di musholla umum pantai Ungapan desa Bajulmati cukup membantu kebutuhan air wudhu pada hari-hari sepi pengunjung atau pada saat warung terdekat tidak berada di lokasi . Pemasangan panel surya $50 \mathrm{WP}$ serta otomatisasi pengaktipan pompa dapat mengurangi beban kerja pemilik warung atau penanggung jawab musholla.

\subsection{Saran}

Berdasar pengamatan selama lebih dari 2 tahun, faktor korosi menjadi permasalahan utama. Sambungan pengawatan dengan terminal baut menjadi berkarat, kontak terputus dan macet, Untuk itu disaranan agar semua perangkat panel surya seperti tiang penyangga, bingkai panel dan baut-baut harus dilapisi cat atau dibungkus isolator atau diganti dengan bahan tahan korosi. Untuk pengaman yang lebih baik, tiap jalur kabel diberi tanda tulisan yang menyatakan polaritas tegangan dan hubungannya terhadap saklar dan beban. Walaupun warna kabel telah dibedakan tetapi tetap ada bagian yang tidak bisa dibedakan berdasar warna, seperti kabel terhadap beban. Diperluan buku manual yang menunjukkan hubungan pengawatan, waktu serta prosedur pengecekan dan penggantian komponen sehingga dapat dipelajari jika terjadi gangguan atau kerusakan.

\section{DAFTAR PUSTAKA}

[1]. Anonim, Sealed Lead Acid Battery Charging Basic, Power Stream Technology, unduh 6 April 2015

[2]. Fathoni, Praktikum Komponen Elektronika, Politeknik Negeri Malang, 2012
[3]. Satwiko S, 2012, Kajian Sel Surya pada Sistem 24 Volt Sebagai Catudaya pada Sistem Pembangkit Tenaga Hybrid, Prosiding Pertemuan Ilmiah XXVI HFI Jateng dan DIY.

[4]. Teguh Utomo, Kajian Kelayakan Sistem Photovolataik Sebagai Pembangkit Daya Listrik Skala Rumah Tangga, Jurnal EECCIS Vol. III No.1. 200 